\title{
NUMERICAL SIMULATION OF MARANGONI-DRIVEN BOUNDARY LAYER FLOW OVER A FLAT PLATE WITH AN IMPOSED TEMPERATURE DISTRIBUTION
}

\author{
Asish Mitra \\ Associate Professor \& HOD-BSH Department, College of Engineering \& Management, Kolaghat. East Midnapur, \\ West Bengal. India \\ mitra_asish@yahoo.com
}

\begin{abstract}
A numerical algorithm is presented for studying Marangoni convection flow over a flat plate with an imposed temperature distribution. Plate temperature varies with $x$ in the following prescribed manner: $T(x, 0)=T_{\infty}+A x^{k+1}$ where $A$ and $k$ are constants. By means of similarity transformation, the original nonlinear partial differential equations of flow are transformed to a pair of nonlinear ordinary differential equations. Subsequently they are reduced to a first order system and integrated using Newton Raphson and adaptive Runge-Kutta methods. The computer codes are developed for this numerical analysis in Matlab environment. Velocity profiles for various values of $k$, and temperature profiles for various Prandtl number and $k$ are illustrated graphically. The results of the present simulation are then compared with the previous works available in literature with good agreement.
\end{abstract}

Keywords: Matlab, Marangoni Convection, Numerical Simulation, Surface Tension, Flat Plate.

\section{List of Symbols}

A constant defined in eq (4a)

a constant defined in eq (6)

$\mathrm{c}_{1}, \mathrm{c}_{2}$ defined in eq (6)

$\mathrm{d}$ constant defined in eq (6)

$f$ function defined in eq (6)

$\mathrm{h}$ constant defined in eq (6)

$\mathrm{k}$ temperature gradient exponent

Pr Prandtl number, dimensionless

$\mathrm{T}$ temperature, $\mathrm{K}$

$\mathrm{T}_{\infty}$ free streams temperature, $\mathrm{K}$

$u$ velocity component in $x, \mathrm{~m} / \mathrm{s}$

$\mathrm{V}$ velocity component in $\mathrm{y}, \mathrm{m} / \mathrm{s}$

$\mathrm{x}$ coordinate from the leading edge, $\mathrm{m}$

$\mathrm{y}$ coordinate normal to plate, $\mathrm{m}$

$\mathrm{z}_{1}, \mathrm{z}_{2}, \mathrm{z}_{3}, \mathrm{z}_{4}, \mathrm{z}_{5}$ variables, eq (11)

\section{Greek Symbols}

$\theta$ function defined in eq (6), dimensionless

$\alpha$ thermal diffusivity, $\mathrm{m}^{2} / \mathrm{s}$

$\mu \quad$ dynamic viscosity, N.s $/ \mathrm{m}^{2}$

$\eta$ similarity variables, defined in eq (6)

$\psi$ stream function, $\mathrm{m}^{2} / \mathrm{s}$

$\rho$ density, $\mathrm{kg} / \mathrm{m}^{3}$

$\sigma$ surface tension, $\mathrm{m} / \mathrm{s}$

\section{INTRODUCTION}

Any variations in temperature or composition result in local variations of surface tension along a liquid free surface and thus induce convective motion. This effect is called Marangoni convection. There have been a number of studies on Marangoni convection over a plate due to its relevance to a variety of industrial applications and naturally occurring processes, such as crystal growth melts, micro-fluidic and integrated DNA analysis devices, extraction processes, flow of sap in the xylem of high trees etc. The earliest analytical investigation in this direction was done by Weber [1], Thomson [2] and Marangoni [3]. Subsequently, this type of convection was studied in various geometries by researchers [4-13].

The objective of the present study is to develop a simple accurate numerical scheme of Marangoni convection flow over a plate with an imposed temperature distribution.

The paper is organized as follows: Mathematical model of the problem, its solution procedure, development of code in Matlab, interpretation of the results, comparison with previous work available in literature.

\section{MATHEMATICAL MODEL}

We consider the Marangoni-driven boundary layer flow over a non-isothermal horizontal flat plate where plate temperature $\mathrm{T}$ varies with $\mathrm{x}$ in the following prescribed manner: $T(x, 0)=T_{\infty}+A x^{k+1}$ where $\mathrm{A}$ and $\mathrm{k}$ are constants. We assume [14] that the surface tension varies linearly with temperature as $\sigma=\sigma_{0}\left[1-\gamma\left(T-T_{0}\right)\right]$, where $\sigma_{0}$ and $T_{0}$ are the characteristics surface tension and temperature, respectively, and we assume that $T_{0}=T_{\infty}$. For most liquids, the surface tension decreases with temperature; that is, $\gamma=-\left(1 / \sigma_{0}\right) \partial \sigma / \partial T$ is a positive fluid property. We also assume the convection flow to be steady, laminar, twodimensional, and the fluid to be Newtonian with constant properties. We take the direction along the plate to be $x$, and the direction normal to surface to be $y$. 
The equations governing the flow are

$\frac{\partial u}{\partial x}+\frac{\partial v}{\partial y}=0$

$u \frac{\partial u}{\partial x}+v \frac{\partial u}{\partial y}=v \frac{\partial^{2} u}{\partial y^{2}}$

$u \frac{\partial T}{\partial x}+v \frac{\partial T}{\partial y}=\alpha \frac{\partial^{2} T}{\partial y^{2}}$

The boundary conditions on the solution are:

At $\mathrm{y}=0$ :

$\left.\mu \frac{\partial u}{\partial y}\right|_{y=0}=-\left.\frac{d \sigma}{d T} \frac{d T}{d x}\right|_{y=0}$

$v(x, 0)=0$

$T(x, 0)=T_{\infty}+A x^{k+1}$

For large y:

$u(x, \infty)=0$

$T(x, \infty)=T_{\infty}$

$4 \mathrm{~b}$

The continuity equation (1) is automatically satisfied through introduction of the stream function:

$u \equiv \frac{\partial \psi}{\partial y} \quad v \equiv-\frac{\partial \psi}{\partial x}$

With the introduction of the following similarity variables

$\eta=c_{1} x^{d} y$

$f(\eta)=c_{2} x^{a} \psi$

$\theta(\eta)=\frac{T(x, y)-T_{\infty} x^{h}}{A}$

6

equations (2) and (3) may be rewritten as (with a prime denoting differentiation with respect to $\eta$ )

$$
\begin{aligned}
& f^{\prime \prime \prime}-a f f^{\prime \prime}-(d-a) f^{\prime^{2}}=0 \\
& \theta^{\prime \prime}-\operatorname{Pr}\left(a f \theta^{\prime}-h f^{\prime} \theta\right)=0
\end{aligned}
$$

where the coefficients and exponents are

$c_{1}=\sqrt[3]{\frac{(d \sigma / d T) A \rho}{\mu^{2}}}$

$c_{2}=\sqrt[3]{\frac{\rho^{2}}{(d \sigma / d T) A \mu}}$

$d=\frac{k-1}{3}$

$a=\frac{-1-k}{3}$

$h=-1-k$
The appropriate boundary conditions are:

at $\eta=0: \quad f=0, \quad f^{\prime \prime}=-1, \quad \theta=1$

at large $\eta: f^{\prime}=0, \quad \theta=0$

\section{SOLUTION PROCEDURE}

Eqs (7) and (8) are nonlinear ordinary differential equations for the velocity and temperature functions, $f^{\prime}$ and $\theta$, and are independent of each other. Eq (7) is solved first and then eq (8). No analytic solution is known, so numerical integration is necessary [15]. There are two unknown initial values at the wall. One must find the proper values of $f^{\prime}(0)$ and $\theta^{\prime}(0)$ which cause the velocity and temperature to their respective free stream values for large $\eta$. The Prandtl number, $\operatorname{Pr}$ and the temperature gradient exponent, $\mathrm{k}$ are parameters.

\subsection{Reduction of Equations to First-order System}

This is done easily by defining new variables:

$z_{1}=f$

$z_{2}=z_{1}^{\prime}=f^{\prime}$

$z_{3}=z_{2}^{\prime}=z_{1}^{\prime \prime}=f^{\prime \prime}$

$z_{3}^{\prime}=z_{2}^{\prime \prime}=z_{1}^{\prime \prime \prime}=f^{\prime \prime \prime}=(d-a) z_{2}^{2}+a z_{1} z_{3} z_{4}=\theta$

$z_{5}=z_{4}^{\prime}=\theta^{\prime}$

$z_{5}^{\prime}=z_{4}^{\prime \prime}=\theta^{\prime \prime}=\operatorname{Pr}\left(a z_{1} z_{5}-h z_{2} z_{4}\right)$

Therefore from eqs (7) and (8), we get the following set of differential equations

$$
\begin{aligned}
& z_{1}^{\prime}=f^{\prime} \\
& z_{2}^{\prime}=z_{1}^{\prime \prime}=f^{\prime \prime} \\
& z_{3}^{\prime}=z_{2}^{\prime \prime}=z_{1}^{\prime \prime \prime}=f^{\prime \prime \prime}=(d-a) z_{2}^{2}+a z_{1} z_{3} \\
& z_{4}^{\prime}=\theta^{\prime} \\
& z_{5}^{\prime}=z_{4}^{\prime \prime}=\theta^{\prime \prime}=\operatorname{Pr}\left(a z_{1} z_{5}-h z_{2} z_{4}\right)
\end{aligned}
$$

Eq (7) is third-order and is replaced by three first-order equations, whereas eq (8) is second-order and is replaced with two first-order equations.

The boundary conditions are then:

$$
\begin{aligned}
& z_{1}(0)=f(0)=0 \\
& z_{2}(\infty)=z_{1}^{\prime}(\infty)=f^{\prime}(\infty)=0 \\
& z_{3}(0)=z_{2}^{\prime}(0)=z_{1}^{\prime \prime}(0)=f^{\prime \prime}(0)=-1 \\
& z_{4}(0)=\theta(0)=1 \\
& z_{4}(\infty)=\theta(\infty)=0
\end{aligned}
$$




\subsection{Solution to Initial Value Problems}

To solve eqs (12), we denote the two unknown initial values by $\mathrm{a}_{1}$ and $\mathrm{a}_{2}$, the set of initial conditions is then:

$z_{1}(0)=f(0)=0$

$z_{2}(0)=z_{1}^{\prime}(0)=f^{\prime}(0)=a_{1}$

$z_{3}(0)=z_{2}^{\prime}(0)=z_{1}^{\prime \prime}(0)=f^{\prime \prime}(0)=-1$

$z_{4}(0)=\theta(0)=1$

$z_{5}(0)=z_{4}^{\prime}(0)=\theta^{\prime}(0)=a_{2}$

If eqs (12) are solved with adaptive Runge-Kutta method using the initial conditions in eq (14), the computed boundary values at $\eta=\infty$ depend on the choice of $\mathrm{a}_{1}$ and $\mathrm{a}_{2}$ respectively. We express this dependence as

$z_{2}(\infty)=z_{1}^{\prime}(\infty)=f^{\prime}(\infty)=f_{1}\left(a_{1}\right)$

$z_{4}(\infty)=\theta(\infty)=f_{2}\left(a_{2}\right)$

The correct choice of $\mathrm{a}_{1}$ and $\mathrm{a}_{2}$ yields the given boundary conditions at $\eta=\infty$; that is, it satisfies the equations

$f_{1}\left(a_{1}\right)=0$

$f_{2}\left(a_{2}\right)=0$

These nonlinear equations are solved by the NewtonRaphson method.

\subsection{Program Details}

This section describes a set of Matlab routines for the solution of eqs (12) along with the boundary conditions (14). They are listed in Table 1.

Table 1. A set of Matlab routines used sequentially to solve Equations (12).

\begin{tabular}{|l|l|}
\hline Matlab code & Brief Description \\
\hline deqs.m & Defines the differential equations (12). \\
\hline incond.m & $\begin{array}{l}\text { Describes initial values for integration, } \\
\mathrm{a}_{1} \text { and } \mathrm{a}_{2} \text { are guessed values, eq (14) }\end{array}$ \\
\hline runKut5.m & $\begin{array}{l}\text { Integrates as initial value problem } \\
\text { using adaptive Runge-Kutta method. }\end{array}$ \\
\hline residual.m & $\begin{array}{l}\text { Provides boundary residuals and } \\
\text { approximate solutions. }\end{array}$ \\
\hline $\begin{array}{l}\text { newtonraphso } \\
\text { n.m }\end{array}$ & $\begin{array}{l}\text { Provides correct values a and } \mathrm{a}_{2} \text { using } \\
\text { approximate solutions from residual.m }\end{array}$ \\
\hline runKut5.m & $\begin{array}{l}\text { Again integrates eqs (12) using correct } \\
\text { values of } \mathrm{a}_{1} \text { and } \mathrm{a}_{2} .\end{array}$ \\
\hline
\end{tabular}

The final output of the code runKut5.m gives the tabulated values of $f, f^{\prime}, f^{\prime \prime}$ as function of $\eta$ for various values of $\mathrm{k}$, and $\theta$ and $\theta^{\prime}$ as function of $\eta$ for various values of Prandtl number and $\mathrm{k}$.

\section{INTERPRETATION OF THE RESULTS}

\subsection{Dimensionless Velocity and Temperature}

\section{Profiles}

Physical quantities are related to the dimensionless functions

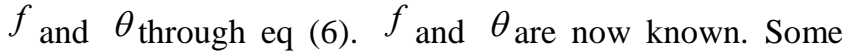
accurate initial values from this computation for velocity and temperature profiles are listed in Tables 2 and 3. From this we can find all the flow parameters of interest to flat plate.

Table 2. Computed values of $f(0)$ and $f^{\prime}(0)$

\begin{tabular}{|l|c|c|c|c|}
\hline & $\mathrm{k}=-0.5$ & $\mathrm{k}=0$ & $\mathrm{k}=1$ & $\mathrm{k}=1.5$ \\
\hline$f(0)$ & 1.7189 & 1.2926 & 1.0000 & 0.9228 \\
\hline$f^{\prime}(0)$ & 2.1184 & 1.4814 & 0.9995 & 0.8754 \\
\hline
\end{tabular}

Table 3. Computed values of $\left.\theta^{\prime}\right|_{\eta=0}$

\begin{tabular}{|l|c|c|c|c|}
\hline & $\mathrm{k}=-0.5$ & $\mathrm{k}=0$ & $\mathrm{k}=1$ & $\mathrm{k}=1.5$ \\
\hline $\mathrm{Pr}=0.001$ & -0.0028 & -0.0026 & -0.0031 & -0.0036 \\
\hline $\mathrm{Pr}=0.002$ & -0.0048 & -0.0050 & -0.0060 & -0.0066 \\
\hline $\mathrm{Pr}=0.004$ & -0.0090 & -0.0098 & -0.0119 & -0.0128 \\
\hline $\mathrm{Pr}=0.006$ & -0.0133 & -0.0147 & -0.0178 & -0.0190 \\
\hline $\mathrm{Pr}=0.008$ & -0.0174 & -0.0195 & -0.0236 & -0.0253 \\
\hline $\mathrm{Pr}=0.01$ & -0.0213 & -0.0243 & -0.0294 & -0.0315 \\
\hline $\mathrm{Pr}=0.02$ & -0.0413 & -0.0476 & -0.0577 & -0.0617 \\
\hline $\mathrm{Pr}=0.04$ & -0.0794 & -0.0921 & -0.1114 & -0.1190 \\
\hline $\mathrm{Pr}=0.06$ & -0.1155 & -0.1338 & -0.1615 & -0.1726 \\
\hline $\mathrm{Pr}=0.08$ & -0.1497 & -0.1731 & -0.2087 & -0.2228 \\
\hline $\mathrm{Pr}=0.1$ & -0.1821 & -0.2102 & -0.2532 & -0.2703 \\
\hline $\mathrm{Pr}=0.2$ & -0.3238 & -0.3716 & -0.4454 & -0.4750 \\
\hline $\mathrm{Pr}=0.4$ & -0.5453 & -0.6192 & -0.7392 & -0.7874 \\
\hline $\mathrm{Pr}=0.6$ & -0.7142 & -0.8130 & -0.9689 & -1.0317 \\
\hline $\mathrm{Pr}=0.8$ & -0.8582 & -0.9765 & -1.1628 & -1.2380 \\
\hline $\mathrm{Pr}=1$ & -0.9848 & -1.1200 & -1.3333 & -1.4194 \\
\hline $\mathrm{Pr}=5$ & -2.4426 & -2.7827 & -3.3165 & -3.5315 \\
\hline $\mathrm{Pr}=10$ & -3.5239 & -4.0208 & -4.7969 & -5.1090 \\
\hline $\mathrm{Pr}=20$ & -5.0495 & -5.7692 & -6.8887 & -7.3384 \\
\hline $\mathrm{Pr}=40$ & -7.2043 & -8.2401 & -9.8458 & -10.4901 \\
\hline $\mathrm{Pr}=60$ & -8.8569 & -10.1356 & -12.1145 & -12.9082 \\
\hline $\mathrm{Pr}=80$ & -10.2499 & -11.7333 & -14.0270 & -14.9467 \\
\hline $\mathrm{Pr}=100$ & -11.4769 & -13.1400 & -15.7119 & -16.7426 \\
\hline
\end{tabular}

Some typical velocity profiles for different values of the temperature gradient exponent $(\mathrm{k})$ obtained using this procedure are shown in Fig 1. 


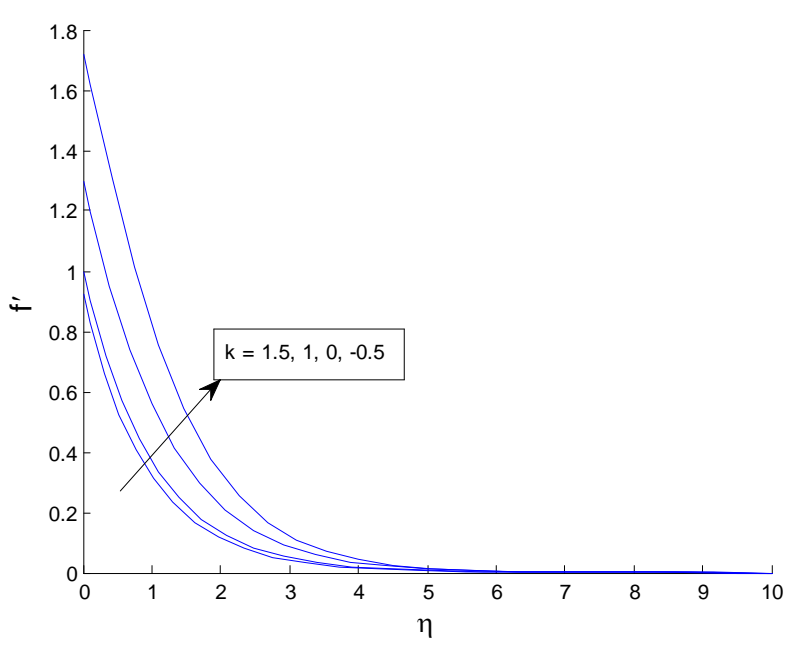

Fig. 1 Dimensionless velocity distributions for various values of $k$.

Variations of $\theta$ with $\eta$ for various values of $\mathrm{k}$ with Prandtl number as parameters obtained from the code are shown in Fig 2.

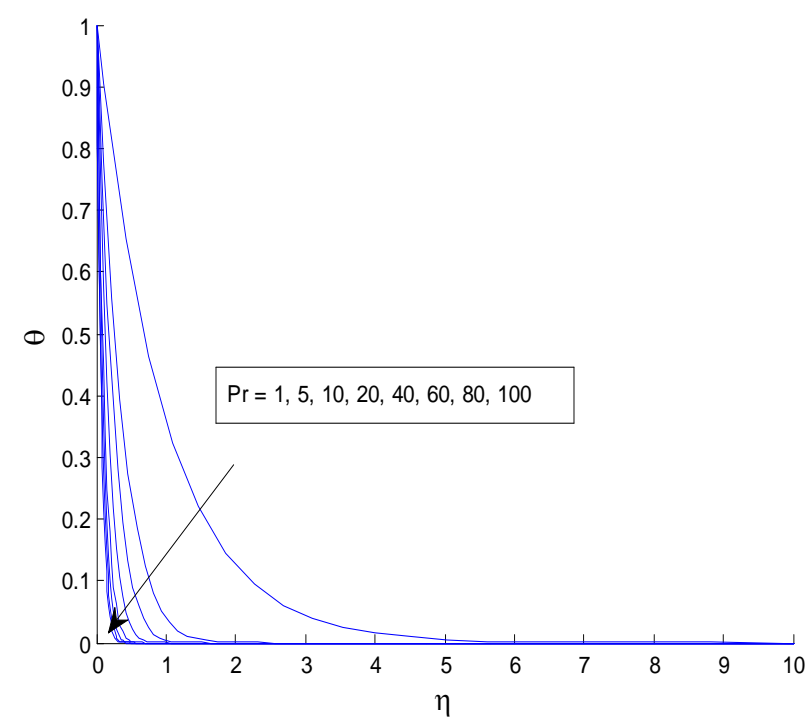

Fig 2a. Solution of $\theta$ for $\mathrm{k}=-0.5$ for high Prandtl numbers.

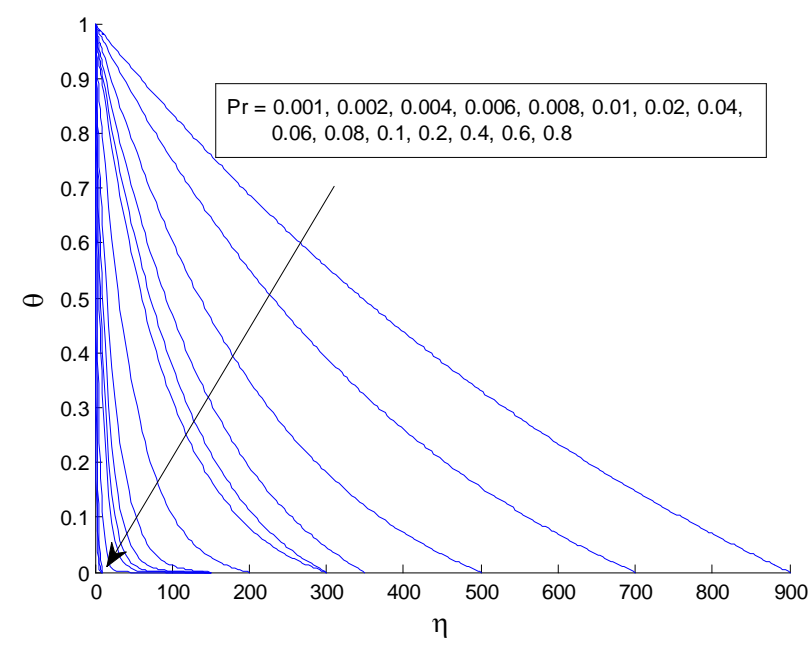

Fig 2b. Solution of $\theta$ for $\mathrm{k}=-0.5$ for low Prandtl numbers.

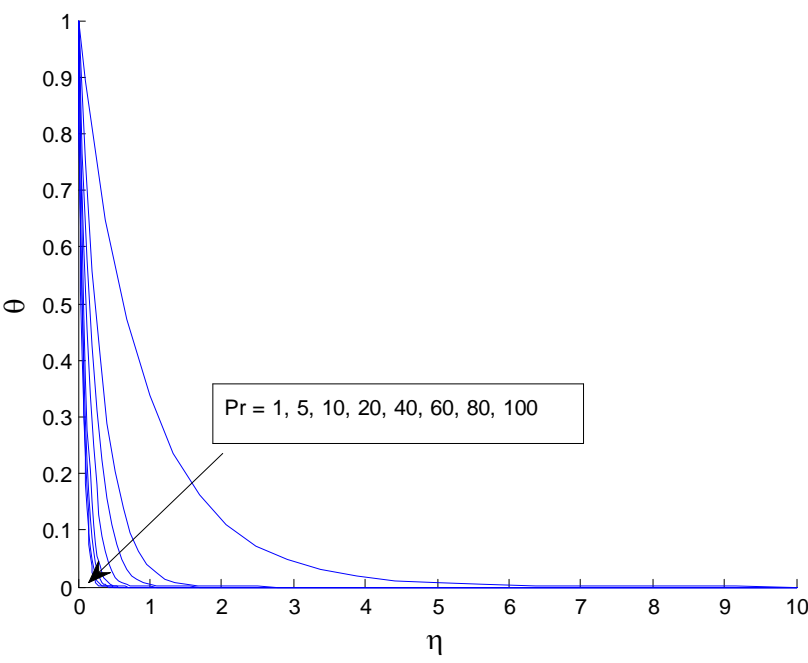

Fig 2c. Solution of $\theta$ for $\mathrm{k}=0$ for high Prandtl numbers.

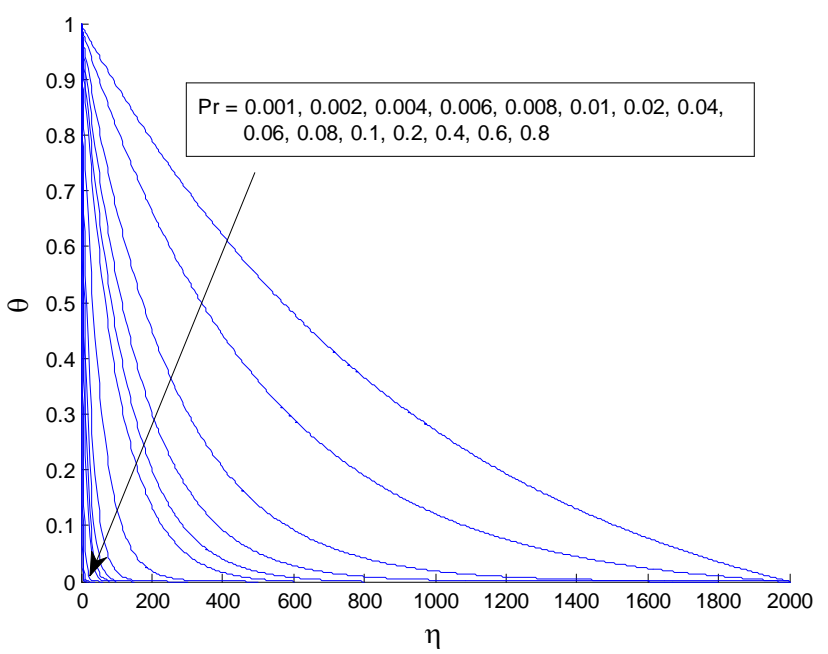

Fig 2d. Solution of $\theta$ for $k=0$ for low Prandtl numbers.

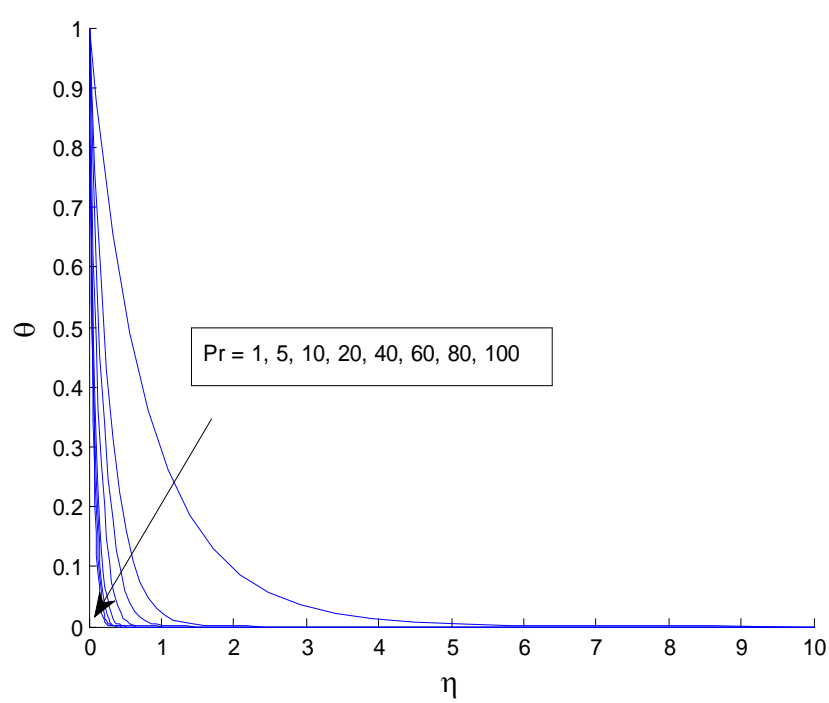

Fig 2e. Solution of $\theta$ for $\mathrm{k}=1$ for high Prandtl numbers. 


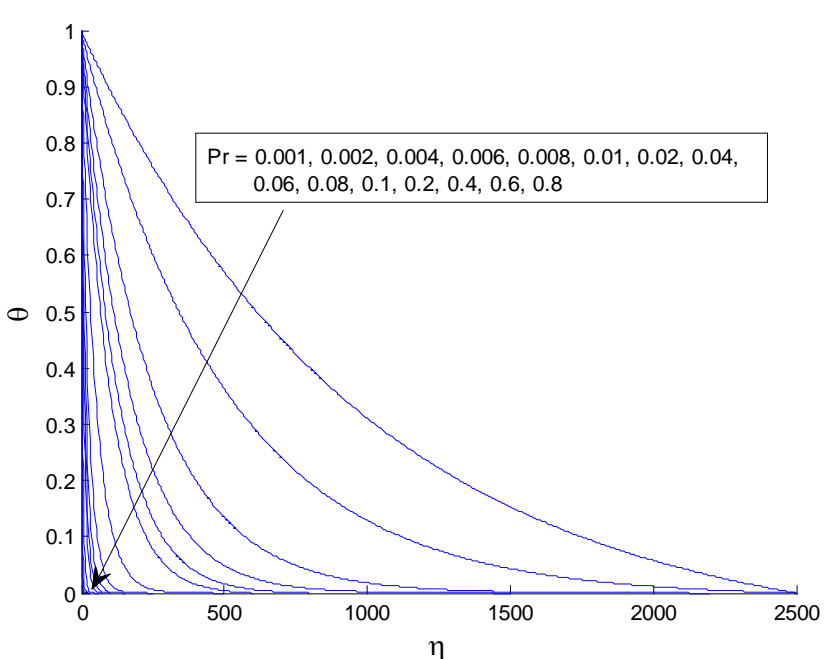

Fig 2f. Solution of $\theta$ for $\mathrm{k}=1$ for low Prandtl numbers.

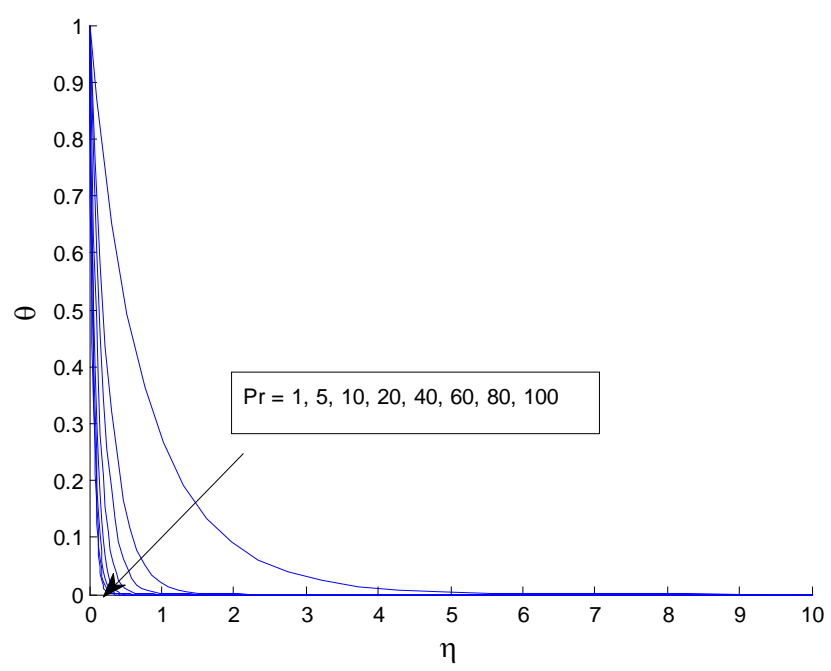

Fig 2g. Solution of $\theta$ for $\mathrm{k}=1.5$ for high Prandtl numbers.

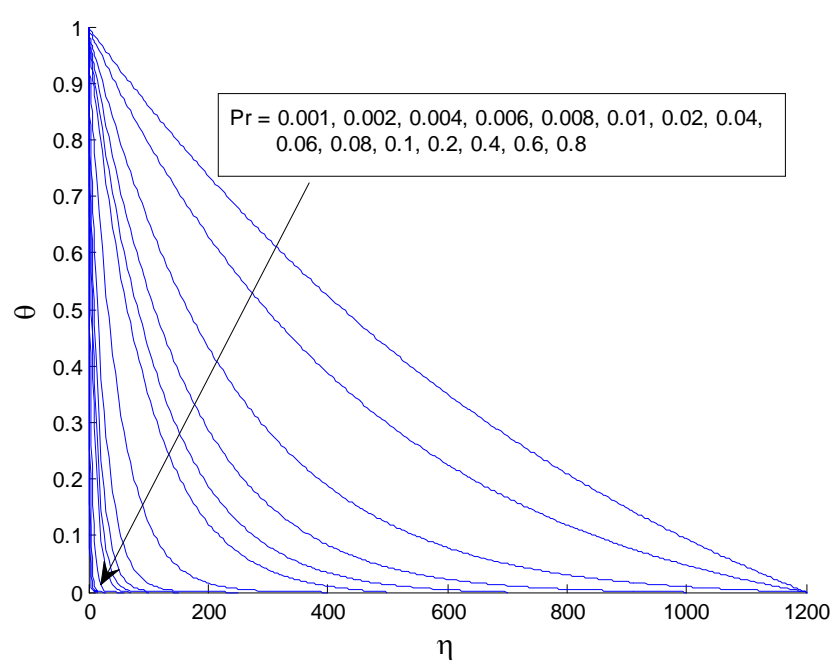

Fig 2h. Solution of $\theta$ for $\mathrm{k}=1.5$ for low Prandtl numbers.

These theoretical profiles (Fig 1 and 2) are in good agreement with the previous works $[16,17]$.

\subsection{Approximate Analysis of the Energy Equation}

In the low Prandtl number region, the thermal boundary layer thickness is much larger than the momentum boundary layer thickness. So, over most of the domain of $\eta, f^{\prime}(\eta)$ is zero and $f(\eta)$ is $f(\infty)$. Hence, energy equation (8) may be approximated as

$\theta^{\prime \prime}(\eta)=\operatorname{Pr} a f(\infty) \theta^{\prime}(\eta)$

Its solution subject to the boundary conditions (10) is

$$
\theta(\eta)=e^{-\operatorname{Pr}((k+2) / 3) f(\infty) \eta}
$$

The temperature gradient at the plate surface is then

$\theta^{\prime}(0)=-\operatorname{Pr}\left(\frac{k+2}{3}\right) f(\infty)$

Therefore, in the low Prandtl number region, the surface temperature gradient $\theta^{\prime}(0)$, should be proportional to the Prandtl number.

In the high Prandtl number region, the thermal boundary layer thickness is much smaller than the momentum boundary layer thickness. So, over most of the domain of $\eta$, $f(\eta)$ is zero and $f^{\prime}(\eta)$ is $f^{\prime}(0)$. Hence, energy equation (8) may be approximated as

$\theta^{\prime \prime}(\eta)=\operatorname{Pr}(k+1) \theta(\eta) f^{\prime}(0)$

Its solution is

$$
\theta(\eta)=e^{-\sqrt{\operatorname{Pr}(k+1) f^{\prime}(0)} \eta}
$$

and temperature gradient at the plate surface is

$$
\theta^{\prime}(0)=-\sqrt{\operatorname{Pr}(k+1) f^{\prime}(0)}
$$

Therefore, in the high Prandtl number region, the surface temperature gradient $\theta^{\prime}(0)$, should be proportional to the square root of Prandtl number.

The variation of surface temperature gradient with Prandtl number for several values of temperature gradient exponent is drawn from

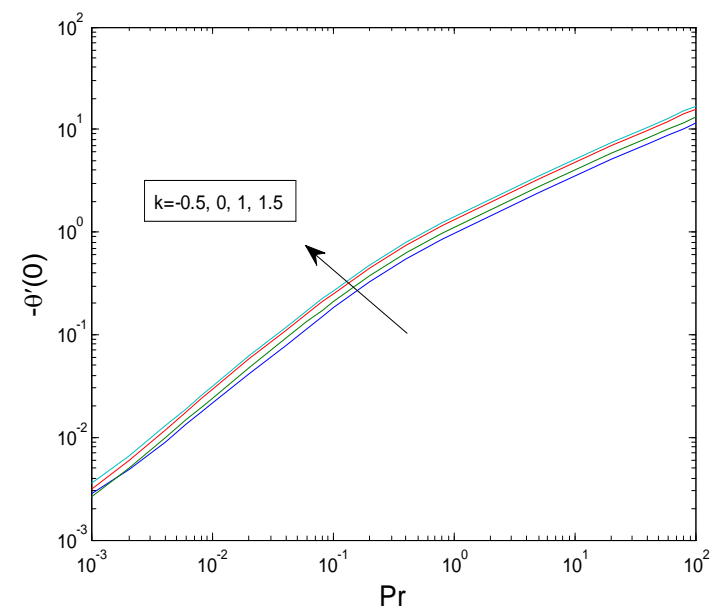

Fig. 3. Variation of surface temperature gradient with $\operatorname{Pr}$ 
Table 3 and shown in Fig 3. The slop of the curve on logarithmic scale is one for small Prandtls and is half for high Prandtl numbers. This agrees well with the findings of previous works $[16,17]$

\section{CONCLUSION}

In the present numerical simulation, Marangoni-driven boundary layer flow over a flat plate with an imposed temperature distribution is presented. Details of the solution procedure of the nonlinear partial differential equations of flow are discussed. The computer codes are developed for this numerical analysis in Matlab environment. Velocity profile, and temperature profiles for Prandtl numbers ranging from 0.001 to 100.0 with temperature gradient exponent, $\mathrm{k}=-0.5,0,1,1.5$ are computed using these codes. The computed velocity and temperature distributions are in very good agreement with results published in literatures indicating that the developed numerical simulation may be an efficient and stable numerical scheme in Marangoni convection.

\section{REFERENCES}

[1] Weber, E. H., Mikroskopische Beobachtungen sehr gesetzm"aßiger Bewegungen, welche dieBildung von Niederschlgen harziger $\mathrm{K}^{*}$ orper aus Weingeist begleiten Berichte "uber die Verhandlungender K"oniglich Schsischen Gesellschaft der Wissenschaften, Mathematisch-Physische Classe, 1854, 57.

[2] Thomson, J., On certain curious motions observable at the surfaces of wine and otheralcoholic liquors, Phil. Mag.1855, 10.

[3] Marangoni, C., "U ber die Ausbreitung der Tropfen einer Fl"ussigkeit auf der Oberfl" ache einer anderen, Ann. Phys. (Leipzig), 1871, 143, 337.

[4] Eyer A., Leist H., Nitsche R., Floating zone growth of silicon under microgravity in a sounding rocket, J. Crystal Growth 711985 173-182.

[5] Straub J., The role of surface tension for two phase heat and mass transfer in the absence of gravity, Experiment. Therm. Fluid Sci. 91994 253-273.

[6] Christopher D., Wang B., Marangoni convection around a bubble in microgravity, heat transfer, in: Lee J.S. (Ed.), Proceedings of the 11th International Heat Transfer Conference, Vol. 3, Taylor \& Francis, Levittown, 1998, pp. 489-494.

[7] Arafune K., Hirata A., Interactive solutal and thermal Marangoni convection in a rectangular open boat, Numer.Heat Tran. Part A 34 (1998) 421-429.

[8] Croll A., Muller-Sebert W., Nitsche R., The critical Marangoni number for the onset of time-dependent convection in silicon, Mater. Res. Bull. 24 (1989) 995-1004. [9] Okano Y., Itoh M., Hirata A., Natural and Marangoni convections in a two-dimensional rectangular open boat, $J$. Chem. Engrg. Japan 22 (1989) 275-281.

[10] Arafune K., Sugiura M., Hirata A., Investigation of thermal Marangoni convection in low and high Prandtl number fluids, J. Chem. Engrg. Japan 32 (1999) 104-109.

[11] Arafune K., Hirata A., Thermal and solutal
Marangoni convection in In-Ga-Sb system, J. Crystal Growth 197 (1999) 811-817.

[12] Slavtchev S., Miladinova S., Thermocapillary flow in a liquid layer at minimum in surface tension, Acta Mechanica 127, 1998, 209-224.

[13] Schwabe D., Metzger J., Coupling and separation of buoyant and thermocapillary convection, J. Crystal Growth1989, 97, 23-33.

[14] Dandapat B. S., Santra B. and Andersson H. I.,

"Thermocapillarity in a liquid film on an unsteady stretching surface," International Journal of Heat and Mass Transfer, vol. 46, no. 16, pp. 3009-3015, 2003.

[15] Mitra A., "Numerical simulation on laminar convection flow and heat transfer over a non-isothermal horizontal plate," International Journal of Research in Engineering \& Technology, 04, 2015, 202-208.

[16] David M. Christopher, Buxuan Wang, "Prandtl number effects for Marangoni convection over a flat surface", Int. J. Therm. Sci. 2001, 40, 564-570

[17] David M. Christopher, Buxuan Wang , Similarity Solution for Convection Heat Transfer Due to Marangoni Flow over a Flat Surface, Tsinghua Science asd Techsology, 2002, 7, $171-176$. 